\title{
CASE SHOWN AT THE F.R.C.S. CLASS.
}

\section{Retroperitoneal Hæmatoma.}

A.M., aged 43 years, single, by occupation a foreman, was admitted to the Charing Cross Hospital on October 7 th, I933.

History of Present Illness: For I3 years he has had attacks of "colicky" or "griping" pain in the upper part of the left side of the abdomen and radiating round to the back. These occur, on the average, every six months and usually when he is in bed. The duration of the attack varies; sometimes it lasts the whole night and is very severe, "doubling him up" and making him restless. Shivering and sweating often occur. There is no relation to the taking of food and neither nausea nor vomiting. After the attack he feels very exhausted. On occasions he is jaundiced after the attack, but not markedly so. The appetite is poor, and there is some flatulence after meals with a tendency to constipation. Micturition is normal. He has lost two stones in weight during the last five weeks.

The last attack occurred about six weeks before admission. It persisted for five weeks, but after the first two days it was relatively mild in severity.

During the last few months there has been, in addition, an indefinite aching and discomfort in both loins, more severe in the left than in the right.

\section{Previous History :}

(I) Operation for left inguinal hernia about twenty-two years ago.

(2) Dysentery during the Great War.

(3) No history of typhoid fever or other serious illness.

Examination : Temperature, $98.6^{\circ} \mathrm{F}$. Pulse, 70 .

$\mathrm{He}$ is a powerfully built man with a sallow complexion and the conjunctivæ slightly jaundiced. Teeth: pyorrhea and two septic roots. Tongue: furred and yellow. Mucosæ of mouth: pale with an icteric tinge. Pupils : equal, react to light and on accommodation. Fauces: injected. Skin: rather moist. No clubbing of fingers.

Inspection.--Respiratory movements good. Scar of operation for left inguinal hernia. Right inguinal hernia. Left costal margin more prominent than the right. Fullness of epigastric region.

Palpation.-Liver and spleen both enlarged and readily palpated below the costal margin. Edge of right lobe of liver about two fingers' breadth below costal margin, firm and regular: surface smooth. Spleen extends about three fingers' breadth below costal margin; border firm; notch not felt. Beneath and below the splenic enlargement a large diffuse mass can be palpated which emerges from beneath and below the splenic border and extends anteriorly towards the middle line of the abdomen, and inferiorly to beyond the level of the umbilicus. Posteriorly it invades the left loin and can be palpated bimanually. The mass, which is tender on deep palpation, has an even consistency and its surface is smooth and regular.

Percussion.-The note over the mass is resonant, as also in both loins.

Scrotum: both testicles normal. Heart and Lungs: nothing abnormal detected. Blood Pressure: $\frac{\text { Sys. } 155 .}{\text { Dias. } 80 .}$ Rectal examination: nothing abnormal detected. 
Urine: Acid; sp.gr. I0I5.

Albumin present.

No pus, blood, sugar or bile.

Special Investigations :

(I) Van den Bergh test (I6.9.33).

Direct reaction-negative.

Indirect reaction-fairly strongly positive.

(2) Fragility of red cells (I6.9.33).

The red cells showed normal resistance to varying concentrations of saline solution. A second test done the day before operation (6.II.33) showed slight diminution in resistance, hæmolysis beginning with $0.5 \%$ sodium chloride, and being complete with $0.35 \%$. With the control blood, hæmolysis began in $0.45 \%$ and was complete in $0.35 \%$ saline solutions.

(3) Blood Count:-

Red cells, 5,490,000 per c.mm.

Hb. $\quad 94 \%$.

Colour Index 0.9 .

White cells 23,300 per c.mm.

Differential Count:-

Polymorphonuclears, $86.67 \%$.

Small Lymphocytes, I2\%.

Large Lymphocytes,

Large Hyalins, $0.67 \%$.

Eosinophils -

Basophils, $0.67 \%$.

A second blood count done on 24.10.33, was very similar, showing 22,800 whites with $5 \%$ of Eosinophils.

(4) Wassermann reaction: negative.

(5) Urea concentration test:-

Ist hour I.99\%-I30 cc.

and hour $2.38 \%-70 \mathrm{cc}$.

3rd hour $2.45 \%-45 \mathrm{cc}$.

(6) Blood Urea: 47 mgms. per Ioo cc.

(7) Casoni's hydatid skin test: negative.

(8) Coagulation time and blood platelet count, Io.II.33 (four days after operation) :

Platelets 490,000 per c.mm.

Coagulation time: $6 \frac{1}{2}$ mins. (Control: 7 mins.).

\section{X-Ray Reports.}

Barium enema:" No obstruction occurred to filling of colon. Descending colon, splenic flexure and left part of transverse colon are disturbed by pressure from a large mass which is situated in the left upper abdomen."

Barium Meal: "Satisfactory function of stomach and duodenum: good progress through small intestine and satisfactory through colon. In prone views of stomach the organ is displaced to the right by some soft tumour mass in the left side." 
Cholecystography: "Non-filling of gall bladder-no stones seen."

Thorax: "Elevation of left dome of diaphragm with displacement upwards of cardiac apex."

Urinary Tract: "No calculus seen."

Instrumental Pyelography: "Slight dilatation of and displacement downwards of left renal pelvis. Ureter displaced to midline (Fig. I). Spleen enlarged. Diagnosis : cortical tumour of lower pole of kidney or extra-renal tumour displacing ureter and causing hydronephrosis."

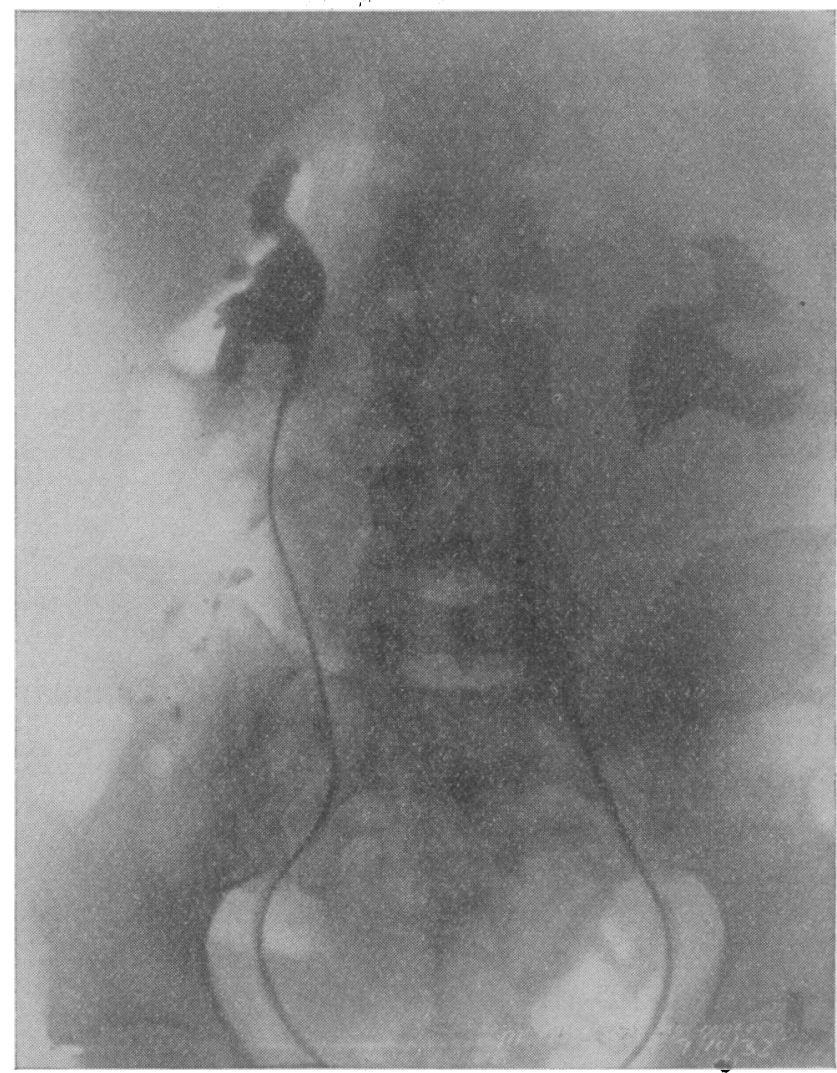

Fig. 1.-Instrumental Pyelography. Left Hydronephrosis with displacement inwards of ureter: diffuse opaque shadow in left lumbar region : enlargement of Liver and Spleen.

Uroselectan B: " Left hydronephrosis with displacement downwards of renal pelvis. Shadow is faint and appears late, indicating defective function in that kidney. Ureter swung towards midline. Shadow seen best at I $I^{3}$ hours. Appearances consistent with a tumour of or near lower pole of kidney and pressing on ureter."

Clinical diagnosis : Extra-renal tumour.

Operation: 6.II.33 Spinal anæsthesia with percaine (I in I500, I5 c.c. L2-3). Left paramedian incision: liver-right lobe enlarged, surface smooth, no cirrhosis, left lobe normal in size: spleen enlarged to about four or five times normal size, 
no perisplenitis: gall bladder soft, èmptied readily on pressure, no stones, normal blue colour and no fibrosis: abdominal glands not enlarged.

A very large cystic retroperitoneal tumour, the size of a small melon, was present behind the mesentery of the descending colon. It appeared to be adjacent and adherent to the lower pole of the left kidney. The tumour was distinct from the spleen. The mesentery of the descending colon was closely adherent to the anterior surface of the tumour. An opening was made through an avascular part of the mesentery and through the wall of the tumour, which was $\frac{1}{8}$-inch thick. It contained dark brownish altered blood and large masses of recent blood clot. The wall of the sac appeared to be intact. The clots were removed, the walls gently scraped and a large drainage tube inserted. A second drainage tube was placed in the recto-vesical pouch and a third in the retroperitoneal space.

Persistent hæmorrhage occurred after the operation. Five blood transfusions, about twelve ounces each, were given on successive days, also hæmoplastin $2 \mathrm{cc}$. coagulen ciba $20 \mathrm{cc}$., and horse serum Io cc., alternatively every four hours. The bleeding gradually ceased and the wound healed by granulation, and the patient was discharged $5 \frac{1}{2}$ weeks after operation.

The splenic enlargement gradually diminished until on discharge it was just palpable on deep inspiration.

The patient was seen again 2.2.34, when the following note was made. " Spleen enlarged about one finger's breadth below costal margin. He looks and feels very well. There have been no further attacks of pain."

\section{Commentary.}

This was an extremely difficult case for diagnosis. The long history of infrequent attacks of "colicky" pain in the left upper abdomen and loin are perhaps suggestive of intermittent hydronephrosis, even in the absence of urinary symptoms. Albumin was present in the urine. The enlarged liver with a history of jaundice following the attacks led his doctor to diagnose gall stones. There was, however, never any alteration in the stools or urine. Banti's disease and acholuric jaundice were both suspected when he attended the out-patient department, but the blood count and fragility test were against either of these conditions. At operation Banti's disease was reconsidered, when it was found that the tumour was a hæmatoma, and the question of removing the spleen was seriously contemplated. There was, however, no cirrhosis of the liver and no ascites, and the spleen was not removed.

Clinically the hæmatoma could readily be palpated bimanually and the majority of the candidates diagnosed a renal tumour, possibly a hydatid or solitary cyst of the lower pole.

It is difficult to account for the occurrence of the hæmatoma. It was most probably due to a ruptured traumatic aneurism of some small retroperitoneal vessel. The Wassermann reaction was negative and there was no history of abdominal trauma except the operation for left inguinal hernia 22 years ago. In this connection it is interesting to note that C. H. Fagge ${ }^{(1)}$ has described a case of retroperitoneal hæmatoma after radical cure of inguinal hernia and varicocele. The hæmatoma occurred Io days after the operation and was due to slipping of the ligature controlling the upper end of the cut pampiniform plexus. In the present case, however, the symptoms occurred 9 years after the operation.

Case presented by A. Cameron MaCLeOd, F.R.C.S.

(1)Fagge, C.H. British Journal of Surgery, 1919-20, VII., 542. 